\title{
Detection of Helicobacter in the fecal material of the endangered Yangtze finless porpoise Neophocaena phocaenoides asiaeorientalis
}

\author{
R. W. McLaughlin ${ }^{1}$, J. S. Zheng ${ }^{2, *}$, M. M. Chen ${ }^{2,3}$, Q. Z. Zhao ${ }^{2}$, D. Wang ${ }^{2}$ \\ ${ }^{1}$ Biology Department, Saint Mary's University of Minnesota, Winona, Minnesota 55987-1399, USA \\ ${ }^{2}$ Institute of Hydrobiology, Chinese Academy of Sciences, Wuhan, 430072, PR China \\ ${ }^{3}$ Graduate School of the Chinese Academy of Sciences, Beijing, 100039, PR China
}

\begin{abstract}
In animals, infection by the Epsilonproteobacteria Helicobacter spp. and H. cetorum is widespread. It has been suggested that $H$. cetorum may cause gastritis in cetaceans. The aim of our study was to investigate the presence of Helicobacter spp. in the fecal material of the endangered Yangtze finless porpoise Neophocaena phocaenoides asiaeorientalis. The fecal material of 12 porpoises living in the wild in Poyang Lake and 1 porpoise living in captivity at the Wuhan Baiji Dolphinarium were examined by PCR for the presence of Helicobacter spp. The fecal material of 8 of 12 wild porpoises and the captive porpoise were positive for Helicobacter spp. as determined by PCR using Helicobacter-specific primers, which target the 16S rRNA gene. A 16S rRNA clone library was then prepared from 1 sample isolated from a female porpoise living in the wild. DNA sequence analysis from 3 of the clones showed 98 to $99 \%$ identity to the $H$. cetorum 16S rRNA gene. These results demonstrate the prevalence of Helicobacter spp. and H. cetorum in endangered freshwater finless porpoises.
\end{abstract}

KEY WORDS: Helicobacter cetorum - Helicobacter spp. · Neophocaena phocaenoides asiaeorientalis · Yangtze finless porpoise $\cdot$ Cetacean

\section{INTRODUCTION}

The finless porpoise Neophocaena phocaenoides inhabits the coastal waters of the Indo-Pacific Oceans (Reeves et al. 1997). Of the 3 subspecies of finless porpoises that are found in Chinese waters (Gao \& Zhou 1995), the Yangtze finless porpoise N. p. asiaeorientalis is the only subspecies which lives in fresh water. Its habitat is restricted to a $1700 \mathrm{~km}$ section of the Yangtze River (from Yichang to Shanghai) and the adjoining lakes. The population size of this porpoise has been rapidly declining due to illegal fishing, pollution, transportation, dam construction, and other detrimental human activities (Wang et al. 2006, Wang 2009). As a result, this marine mammal is an endangered species and is listed in the IUCN Red Data Book as a threatened species (Hilton-Taylor 2000).
Infectious diseases significantly impact cetacean populations (Van Bressem et al. 2009). In harbor porpoises, high exposure to polychlorinated biphenyls (PCBs) increases the risk of mortality from infectious disease (Hall et al. 2006). Potential important microparasites of cetaceans are Helicobacter spp. (Van Bressem et al. 2009), which are members of the Epsilonproteobacteria. These bacteria are Gram-negative, microaerobic, fusiform, or slightly curved to spiral, and motile (Fox 2002). Helicobacter spp. are able to naturally colonize the lower intestinal tract of an animal host and can cause typhlitis or colitis. In the majority of cases, helicobacter infections produce subclinical inflammation in a naturally infected host. However, significant inflammation and even cancer can result in some cases. For example, $H$. pylori is able to colonize the stomach in humans and has been shown to cause 
peptic ulcer disease, gastritis, and gastric cancer (Marshall 2002). In ferrets, H. mustelae can cause chronic gastritis (Fox et al. 1990). H. cetorum has been isolated from the fecal material and main stomach of both stranded and captive cetaceans. In cetaceans, the bacterium is associated with gastritis (Harper et al. 2002a,b). However, H. cetorum infection has also been demonstrated in clinically healthy cetaceans (Harper et al. 2000).

PCR with Helicobacter cetorum-specific primers has been used to detect $H$. cetorum in the fecal material or gastric fluid of a wide range of captive and wild cetaceans, including the Atlantic bottlenose dolphin Tursiops truncatus, the Atlantic white-sided dolphin Lagenorhynchus acutus, the Pacific white-sided dolphin L. obliquidens, and the beluga whale Delphinapterus leucas (Harper et al. 2000). Recently, Helicobacter was detected in the digestive tract of a stranded Atlantic spotted dolphin Stenella frontalis (Suárez et al. 2010). However, to date no Helicobacter spp. have been detected in porpoises.

The intestinal microbiota play an important role in health and disease of the host, and intestinal pathogens can certainly negatively impact cetacean populations (Falk et al. 1998, Birkun 2002, Van Bressem et al. 2009). The development of disease is influenced by the intestinal microbiota, as well as the immune status and the genetic makeup of the host (Falk et al. 1998, Hooper et al. 2001, Marshall 2002). The microbiota provide nutritional substrates, aid in modulating the immune system, and help prevent infections by intestinal pathogens, all to the benefit of the host (Falk et al. 1998, Hooper et al. 2001). Understanding the intestinal micobiota has a direct bearing on our ability to manage and maintain health in humans and in cetaceans (Dethlefsen et al. 2006, Van Bressem et al. 2009). Although several studies have suggested that the intesti- nal microbiota differs along various regions of the gastrointestinal tract (Suchodolski et al. 2005, Ritchie et al. 2008), fecal samples are much easier and more practical to collect. Therefore, in the present study we examined the presence of Helicobacter in the fecal material of the Yangtze finless porpoise in an attempt to learn more about the health of this endangered species.

\section{MATERIALS AND METHODS}

Sample collection. Fecal samples were collected between 2 and 11 March 2010 from 12 Yangtze finless porpoises living in the wild at Poyang Lake. Six were females and ranged in age from 0.1 to $13.8 \mathrm{yr}$. Six porpoises were male and ranged in age from 1.0 to $7.3 \mathrm{yr}$. Fecal material was also collected from 1 porpoise during a routine medical examination in June 2010. This porpoise was born and has resided in the Wuhan Baiji Dolphinarium since July 2005 (Wang et al. 2005). Table 1 outlines the important characteristics of the porpoises used in this study.

A non-invasive method was applied to collect fecal samples following the steps described below. Firstly, the porpoise was kept in a suitable environment and in a stable position. The anus was cleaned using $70 \%$ ethanol, and a sterile soft plastic tube $4 \mathrm{~mm}$ in diameter was inserted through the anus and allowed to travel about $20 \mathrm{~cm}$ into the intestine. The tube was then removed, along with any fecal material collected, and cut into sections. Sections that did not contain fecal material were discarded, and sections containing fecal material were placed in a sterilized $1.5 \mathrm{ml}$ Eppendorf tube. All capture, handling, and sampling operations were approved by the Administrative Department of Fisheries Management of Jiangxi Province, where Poyang Lake is located. All samples were kept in con-

Table 1. Neophocaena phocaenoides asiaeorientalis. Information on the sampled Yangtze finless porpoises used in this study. Age was estimated by body length according to experimental formulas described by Zhang (1992). PYL: Poyang Lake, WHBD: Wuhan Baiji Dolphinarium; F: female; M: male

\begin{tabular}{|lcccccc|}
\hline Animal code & Location & Sex & Body length $(\mathrm{cm})$ & Weight $(\mathrm{kg})$ & Age (yr) & Note \\
\hline 10PYF1 & PYL & F & 138.0 & 50.6 & 6.1 & Well nourished \\
10PYF2 & PYL & F & 95.0 & 18.8 & 0.1 & Neonate \\
10PYF4 & PYL & F & 149.0 & 63.6 & 13.8 & Well nourished \\
10PYF6 & PYL & F & 146.0 & 62.7 & 11.1 & Well nourished \\
10PYF8 & PYL & F & 140.0 & 47.4 & 7.1 & Adult \\
10PYF10 & PYL & F & 141.0 & 42.6 & 6.7 & Adult \\
10PYM1 & PYL & M & 149.0 & 38.1 & 3.9 & Skinny adult \\
10PYM4 & PYL & M & 114.0 & 47.4 & Yearling \\
10PYM5 & PYL & M & 151.5 & 31.6 & 2.1 & Well nourished \\
10PYM6 & PYL & M & 127.0 & 37.8 & 2.2 & Juvenile \\
10PYM7 & PYL & M & 128.0 & 33.3 & 1.3 & Juvenile \\
10PYM8 & PYL & M & 119.0 & 39.6 & 5.0 & Juvenile \\
TT & WHBD & M & 143.5 & & Adult \\
\hline
\end{tabular}


tainers at $0^{\circ} \mathrm{C}$ during transport, and stored at $-80^{\circ} \mathrm{C}$ until DNA extraction.

PCR of fecal samples using Helicobacter-specific primers. DNA was extracted from feces using the ZR Fecal DNA kit (Zymo Research) according to the manufacturer's instructions. Two PCR amplifications were done. The first amplification was done using all 13 DNA samples. We used the Helicobacter-specific primers F0 5'-GAG TTT GAT CCT GGC TCA GAG-3' and R0 5'-AAC CTT CAT CCT CCA CGC-3', which amplify an approximately 400 bp fragment of the $16 \mathrm{~S}$ rRNA gene (Goldman et al. 2009). The PCR mixture with a final volume of $25 \mu$ l contained $1 \times$ Taq polymerase buffer, $0.5 \mu \mathrm{M}$ of each primer, $2.5 \mathrm{mM} \mathrm{MgCl}_{2}$, $0.2 \mathrm{mM}$ dNTPs, 0.25 U Taq DNA polymerase (Biostar), and $2 \mu \mathrm{l}(80 \mathrm{ng})$ fecal DNA. The PCR cycling conditions included an initial denaturation at $94^{\circ} \mathrm{C}$ for $5 \mathrm{~min}$, followed by 30 cycles of $94^{\circ} \mathrm{C}$ for $30 \mathrm{~s}, 59^{\circ} \mathrm{C}$ for $30 \mathrm{~s}$, and $72^{\circ} \mathrm{C}$ for $30 \mathrm{~s}$, and a final extension at $72^{\circ} \mathrm{C}$ for $5 \mathrm{~min}$ using a TC-5000 gradient thermo cycler (Bibby Scientific). A $10 \mu \mathrm{l}$ aliquot was subject to electrophoresis through a $2.0 \%(\mathrm{wt} / \mathrm{vol})$ agarose gel which contained ethidium bromide. PCR products were visualized under UV light.

16S rRNA gene clone library construction. The second amplification was done with 1 DNA sample, isolated from the fecal material of a female Yangtze finless porpoise living in the wild. The universal primers fD1 5'-AGA GTT TGA TCC TGG CTC AG-3', positions 7 to 26 in the Escherichia coli 16S rRNA gene, and rP2 5'-ACG GCT ACC TTG TTA CGA CTT-3', positions 1513 to 1494 , were used. This primer combination produces an approximate $1500 \mathrm{bp}$ fragment (Weisburg et al. 1991). The PCR mixture with a final volume of $25 \mu \mathrm{l}$ contained $1 \times$ Taq polymerase buffer, $0.5 \mu \mathrm{M}$ of each primer, $2.5 \mathrm{mM} \mathrm{MgCl} 2,0.2 \mathrm{mM}$ dNTPs, $0.25 \mathrm{U}$ Taq DNA polymerase (Biostar), and $2 \mu \mathrm{l}$ fecal DNA. The PCR cycling conditions included an initial denaturation at $95^{\circ} \mathrm{C}$ for $6 \mathrm{~min}$, followed by 30 cycles of $94^{\circ} \mathrm{C}$ for $1 \mathrm{~min}, 56^{\circ} \mathrm{C}$ for $1 \mathrm{~min}$, and $72^{\circ} \mathrm{C}$ for $2 \mathrm{~min}$, and a final extension at $72^{\circ} \mathrm{C}$ for $10 \mathrm{~min}$.

An approximately $1500 \mathrm{bp}$ PCR product was purified with the DNA Purification Kit (Bioteke) according to the manufacturer's instructions. Purified PCR products were cloned into pMD18-T vectors (Takara) and transformed into E. coli DH5 $\alpha$ competent cells following the manufacturer's recommendation. Clones were checked for a correct insert size by PCR. The PCR mixture with a final volume of $15 \mu \mathrm{l}$ contained $1 \times$ Taq polymerase buffer, $0.5 \mu \mathrm{M}$ of universal T-vector primers (M13+ and M13-), $0.2 \mathrm{mM}$ dNTPs, 0.2 U Taq DNA polymerase (Biostar), and $2 \mu$ bacterial supernatant. The PCR cycling conditions included an initial denaturation at $95^{\circ} \mathrm{C}$ for $5 \mathrm{~min}$, followed by 30 cycles of $95^{\circ} \mathrm{C}$ for $30 \mathrm{~s}, 54^{\circ} \mathrm{C}$ for $30 \mathrm{~s}$, and $72^{\circ} \mathrm{C}$ for $2 \mathrm{~min}$, and a final ex- tension at $72^{\circ} \mathrm{C}$ for $7 \mathrm{~min}$. Sequencing was then done with the BigDye terminator cycle sequencing ready reaction kit (Applied Biosystem) using M13 forward and reverse primers on an $\mathrm{ABI}^{\circledR} 3730$ automated DNA sequencer. In total, 5 positive clones were sequenced.

Data analysis. Sequences were assembled using the software DNA Baser version 3 (HeracleSoftware) and edited to remove vector contamination and primer sequences. For sequence identification, cloned sequences were compared to the 16S rRNA of existing organisms using the NCBI database and the Ribosomal Database Project Classifier. For phylogenetic analysis, 16S rRNA sequences were retrieved from GenBank of different Helicobacter species. All sequences were edited to a common length and aligned using the CLUSTAL-W program. The program MEGA version 4 (Tamura et al. 2007) was used to create a phylogenetic tree by the neighbor-joining method. To test the stability of the groups, a bootstrap analysis of 10000 replications was done.

\section{RESULTS}

PCR results, using Helicobacter-specific primers, showed amplification of the expected $400 \mathrm{bp}$ fragment for the majority of fecal samples of Yangtze finless porpoises living in the wild and from 1 porpoise (TT) living in captivity (Fig. 1). For the porpoises living in the wild, the fecal samples of all 6 females (F1, F2, F4, F6, F8, and F10) and 2 males (M4 and M8) showed definite positive PCR results. The fecal samples of 2 males (M6 and M7) gave negative PCR results, whereas 2 other males (M1 and M5) showed inconclusive results. Universal primers were used to amplify the 16S rRNA gene from the bacterial DNA isolated from the fecal material of 1 Yangtze finless porpoise, F2 (Fig. 1), to construct a clone library. Three different sequences from the clone library (R2-1, R2-9, and R2-10; GenBank accession numbers HQ335340HQ335342) were obtained, and using the Ribosomal Database Classifier, the phylogenetic affiliation for all 3 clones was determined to be the genus Helicobacter. Pairwise sequence comparisons to sequences deposited in the GenBank nucleotide database using the BLAST algorithm indicated that both R2-1 and R2-9 showed $99 \%$ identity to $H$. cetorum partial $16 \mathrm{~S}$ rRNA gene, isolate 24/M74/10/09 (FN565165) and to Helicobacter sp. MIT 99-5657 (AF292377) 16S rRNA gene, partial sequence. Sequence R2-10 showed 98\% identity to $H$. cetorum partial $16 \mathrm{~S}$ rRNA gene, isolate 22/M47/10/08 (FN565163). Isolates 22/M47/10/08 and 24/M74/10/09 were both obtained from common dolphins inhabiting the southwest coast of England (A. M. Whatmore pers. comm.). MIT 99-5657 was obtained 


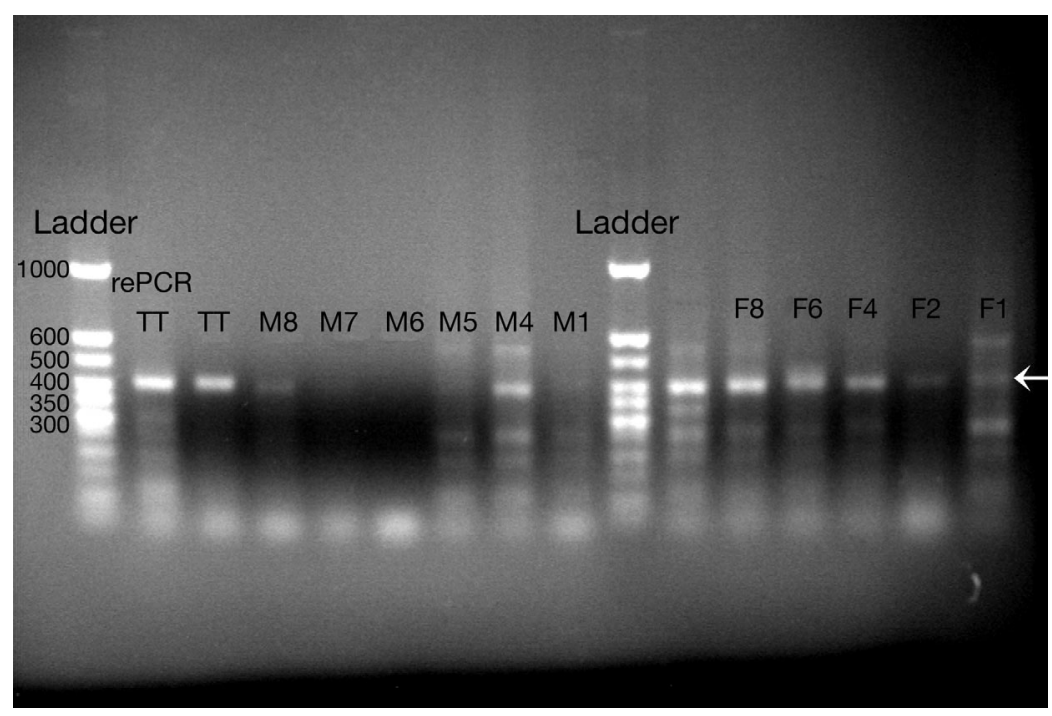

Fig. 1. PCR amplification of DNA isolated from the fecal material of 12 wild Yangtze finless porpoises from Poyang Lake and 1 captive porpoise from the Wuhan Baiji Dolphinarium (TT). We used Helicobacter-specific primers to amplify a $\sim 400$ bp fragment of the 16S rRNA gene. rePCR: second PCR amplification. Arrow indicates the $\sim 400 \mathrm{bp}$ band

from the gastric mucosa of 2 stranded Atlantic whitesided dolphins Lagenorhynchus acutus (Harper et al. 2000).

The specialized BLAST alignment tool was then used to compare nucleotide differences in sequences R2-1，R2-9, and R2-10. Alignment of the sequences revealed that R2-1 and R2-9 differed by 5 bases. Sequences R2-1 and R2-10 differed at 29 positions, and sequences R2-9 and R2-10 differed at 26 positions. A tree illustrating the phylogenetic location of sequences R2-1, R2-9, and R2-10 compared to 9 other species of the genus Helicobacter is shown in Fig. 2.

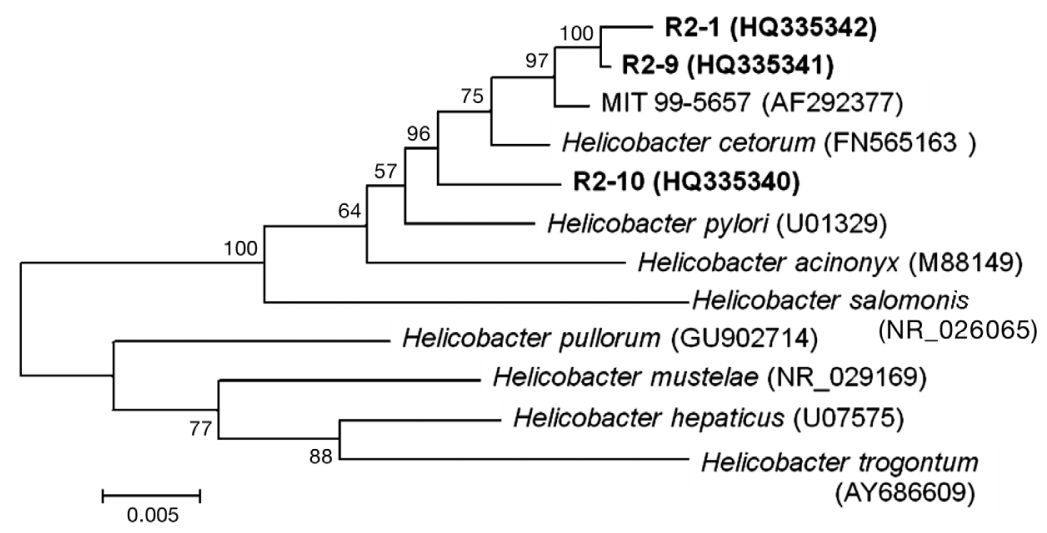

Fig. 2. Dendrogram based on an approximately 1420 bp segment of 16S rRNA gene sequence. Phylogenetic location of Helicobacter cetorum from a Yangtze finless porpoise shown in bold. GenBank accession numbers are in parentheses. Scale bar indicates a 0.5\% difference in nucleotide sequences. MIT 99-5657 was isolated from the main stomach of an Atlantic white-sided dolphin
In this study, only a small number of positive clones were sequenced from the clone library. However, 3 of the 5 clones sequenced showed identity to Helicobacter. This unexpected observation led us to focus the remainder of this study on Helicobacter. Subsequent studies will address the bacterial diversity found within the clone libraries from the porpoise fecal samples.

\section{DISCUSSION}

In this preliminary study, we confirmed the presence of Helicobacterspp. in the fecal material of several Yangtze finless porpoises. We also identified that $H$. cetorum was present in 1 fecal sample. A phylogenetic tree of the three 16S rRNA sequences (R2-1, R2-9, and R2-10) showed a similar phylogenetic location, clustering near $H$. cetorum. Interestingly, the partial 16S rRNA gene sequence of Helicobacter sp. MIT 99-5657 is $100 \%$ identical to $H$. cetorum partial 16S rRNA gene, isolate 24/M74/10/09. Isolates 24/M74/10/09 and 22/ M47/10/08 are $99 \%$ identical (data not shown).

Helicobacter cetorum is able to effectively colonize several different cetaceans, including many different species of dolphins, the beluga whale, and now the Yangtze finless porpoise. How the mechanisms of Helicobacter transmission function is a question which must be addressed. In a recent study, Helicobacter spp. DNA was detected in aquatic environments. It was suggested that regurgitated fish otoliths and perhaps other tissues caused bacterial contamination of the water, which aided in the transmission of Helicobacter in marine mammals (Goldman et al. 2009). In our study, the fecal material of 1 porpoise living in captivity tested positive for the presence of Helicobacter spp. The porpoises housed in the Wuhan Baiji Dolphinarium are commonly fed different species of carp. Perhaps some carp are infected with Helicobacter and the infection is passed to the porpoises as a result of ingesting the fish. In addition, according to our rearing and autopsy experiences over the past $20 \mathrm{yr}$, peptic ulcer disease and gastritis are the most common diseases which cause Yangtze finless porpoises to become malnourished or even die. Both the morbidity and mortality 
rate are higher than $50 \%$ for porpoises living in the wild, and the morbidity rate is even higher for porpoises living in captivity. Based on current knowledge about gastric helicobacter infections, it is probable that the Helicobacter spp. and $H$. cetorum identified in this study play a role in the etiopathogenesis of gastritis in porpoises. Future studies examining the pathogenesis of $H$. cetorum could help in understanding the potential role of this bacterium in the health of these animals. However, future studies will need to be done to address both of these topics. For example, when gastric mucosa tissue becomes available from autopsied Yangtze finless porpoises, the tissues will be assessed by PCR for Helicobacter spp. and H. cetorum. Most importantly, a non-invasive molecular procedure, such as quantitative PCR using Helicobacter spp. and $H$. cetorum-specific primers, will be developed to diagnose this kind of pathogen in fecal material. Infected endangered finless porpoises will be identified and treated to prevent these animals from suffering, becoming malnourished, and possibly dying.

Acknowledgements. We thank B. Bratina (University of Wisconsin-La Crosse) for reviewing the manuscript and for very helpful insight. We also thank Y. J. Hao, A. H. Guo, J. Z. Wang, W. M. Gong, and several other colleagues for help in fecal sample collection. The experimental work was conducted in the molecular laboratory of the Research Group on Conservation Biology of Aquatic Animals at the Institute of Hydrobiology, the Chinese Academy of Sciences. This project was supported by grants from the National Natural Science Foundation of China (No. 30730018) and the National Basic Research Program of China (No. 2007CB411600).

\section{LITERATURE CITED}

Birkun AA Jr (2002) The current status of bottlenose dolphin (Tursiops truncatus) in the Black Sea. Report MOP 1/inf. 8 of the ACCOBAMS First Meeting of the Parties, 28 Feb 2002, Monaco

Dethlefsen L, Eckburg PB, Bik EM, Relman DA (2006) Assembly of the human intestinal microbiota. Trends Ecol Evol 21:517-523

Falk PG, Hooper LV, Midtvedt T, Gordon JI (1998) Creating and maintaining the gastrointestinal ecosystem: what we know and need to know from gnotobiology. Microbiol Mol Biol Rev 62:1157-1170

Fox JG (2002) The non-H pylori helicobacters: their expanding role in gastrointestinal and systemic diseases. Gut 50: $273-283$

Fox JG, Correa P, Taylor NS, Lee A, Otto G, Murphy JC, Rose R (1990) Helicobacter mustelae-associated gastritis in ferrets. An animal model of Helicobacter pylori gastritis in humans. Gastroenterology 99:352-361

Gao A, Zhou K (1995) Geographical variation of external measurements and three subspecies of Neophocaena phocaenoides in Chinese waters. Acta Theriol Sin 15:81-92 (in Chinese with English abstract)

Goldman CG, Loureiro JD, Matteo MJ, Catalano M and others (2009) Helicobacter spp. from gastric biopsies of stranded South American fur seals (Arctocephalus australis). Res Vet Sci 86:18-21
Hall AJ, Hugunin K, Deaville R, Law RJ, Allchin CR, Jepson PD (2006) The risk of infection from polychlorinated biphenyl exposure in the harbor porpoise (Phocoena phocoena): a case-control approach. Environ Health Perspect 114:704-711

Harper CM, Dangler CA, Xu S, Feng Y and others (2000) Isolation and characterization of a Helicobacter sp. from the gastric mucosa of dolphins, Lagenorhynchus acutus and Delphinus delphis. Appl Environ Microbiol 66:4751-4757

Harper CM, Xu S, Feng Y, Dunn JL, Taylor NS, Dewhirst FE, Fox JG (2002a) Identification of novel Helicobacter spp. from a beluga whale. Appl Environ Microbiol 68: 2040-2043

> Harper CG, Feng Y, Xu S, Taylor NS and others (2002b) Helicobacter cetorum sp. nov., a urease-positive Helicobacter species isolated from dolphins and whales. J Clin Microbiol 40:4536-4543

Hilton-Taylor C (2000) 2000 IUCN Red List of Threatened Species. IUCN, Gland

> Hooper LV, Wong MH, Thelin A, Hansson L, Falk PG, Gordon JI (2001) Molecular analysis of commensal host-microbial relationships in the intestine. Science 291:881-884

- Marshall B (2002) Helicobacter pylori: 20 years on. Clin Med 2:147-152

Reeves RR, Wang JY, Leatherwood S (1997) The finless porpoise, Neophocaena phocaenoides (G. Cuvier, 1829): a summary of current knowledge and recommendations for conservation action. Asian Mar Biol 14:111-143

- Ritchie LE, Steiner JM, Suchodolski JS (2008) Assessment of microbial diversity along the feline intestinal tract using 16S rRNA gene analysis. FEMS Microbiol Ecol 66: 590-598

Suárez P, Contreras M, Fernández-Delgado M, Salazar V, Peña R, Michelangeli F, García-Amado MA (2010) Detection of Helicobacter in the digestive tract of an Atlantic spotted dolphin (Stenella frontalis). J Wildl Dis 46:622-626

> Suchodolski JS, Ruaux CG, Steiner JM, Fetz K, Williams DA (2005) Assessment of the qualitative variation in bacterial microflora among compartments of the intestinal tract of dogs by use of a molecular fingerprinting technique. Am J Vet Res 66:1556-1562

Tamura K, Dudley J, Nei M, Kumar S (2007) MEGA4: Molecular Evolutionary Genetics Analysis (MEGA) software version 4.0. Mol Biol Evol 24:1596-1599

Van Bressem MF, Raga JA, Di Guardo G, Jepson PD and others (2009) Emerging infectious diseases in cetaceans worldwide and the possible role of environmental stressors. Dis Aquat Org 86:143-157

> Wang D (2009) Population status, threats and conservation of the Yangtze finless porpoise. Chin Sci Bull 54: 3473-3484

> Wang D, Hao Y, Wang K, Zhao Q, Chen D, Wei Z, Zhang X (2005) The first Yangtze finless porpoise successfully born in captivity. Environ Sci Pollut Res 12:247-250

Wang K, Wang D, Zhang X, Pfluger A, Barrett L (2006) Range-wide Yangtze freshwater dolphin expedition: the last chance to see Baiji? Environ Sci Pollut Res 13: 418-424

Weisburg WG, Barns SM, Pelletier DA, Lane DJ (1991) $16 \mathrm{~S}$ ribosomal DNA amplification for phylogenetic study. J Bacteriol 173:697-703

Zhang X (1992) Studies on the age determination, growth and reproduction of finless porpoise Neophocaena phocaenoides. Acta Hydrobiol Sin 16:289-298 (in Chinese with English abstract) 